- Clinicians have an important role in advising patients about toothbrushing. By modifying this well accepted habit significant increases in health benefit can be gained.

- Caries reductions can be increased by increasing brushing frequency, using higher concentration fluoride formulations and limiting rinsing

- Periodontal disease can be controlled by teaching effective twice daily brushing, advising the correct design brush and toothpaste.

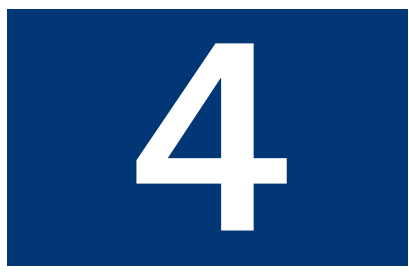

VERIFIABLE

CPD PAPER

\title{
Prevention. Part 4: Toothbrushing: What advice should be given to patients?
}

\author{
R. M. Davies ${ }^{1}$, G. M. Davies ${ }^{2}$ and R. P. Ellwood ${ }^{3}$; Series Editor E. J. Kay ${ }^{4}$
}

\begin{abstract}
This paper examines and summarises the evidence to support the advice that GDPs should give their patients on toothbrushing. The strength of evidence is graded using a five-point hierarchical scale. Much of the evidence to support toothbrushing advice is relatively weak but the increasing number of high quality systematic reviews will gradually improve the strength of evidence to support effective programmes of preventive care. Clinicians can play an important role in maximising the benefits of toothbrushing with fluoride toothpaste for patients of all ages. This well-accepted health behaviour can, if implemented correctly, reduce the establishment and advance of the two major dental diseases.
\end{abstract}

\section{PREVENTION}

1. Smoking cessation advice

2. Dietary advice

3. Prevention of tooth wear

4. Toothbrushing advice

5. Patients requiring osseointegrated oral implant treatment

6. Older dentate patient

7. Professionally applied topical fluorides for caries prevention

8. Pit and fissure sealants in preventing caries in the permanent dentition of children

${ }^{1}$ Director, ${ }^{3}$ Technology Manager, Dental Health Unit, Manchester, UK; ${ }^{2}$ Senior Dental Officer (Epidemiology), Central Manchester Primary Care Trust, Manchester ${ }^{4}$ Professor of Dental Health Services Research, University of Manchester Dental Hospital and School, Higher Cambridge Street, Manchester M15 6FH

Correspondence to: R. M. Davies, Dental Health Unit, Manchester Science Park, Lloyd Street North, Manchester M15 6SH E-mail: robin.davies@man.ac.uk

\section{Refereed Paper}

doi:10.1038/sj.bdj.4810396

๑ British Dental Journal 2003; 195:

135-141
Twice daily brushing with a fluoride toothpaste has been widely promoted by the profession for many years since it plays a pivotal role in the prevention and control of dental caries and periodontal diseases. Such behaviour, although selfreported, appears to be an integral part of many people's daily hygiene routine. In Great Britain $55 \%$ of children aged 1.5 to 4.5 years were reported to have their teeth brushed more than once a day ${ }^{1}$ and in the UK $64 \%$ of 4 to 18 year olds ${ }^{2}$ and $74 \%$ of dentate adults claimed to brush their teeth twice a day. ${ }^{3}$ Whilst it is generally accepted that such behaviour has been the most important contributor to the improvement in the dental health of the nation a sizeable proportion of the population still do not even claim to brush twice daily.

Contrary to the prevailing view that caries is under control the disease poses a potential threat throughout the lifetime of the individual. In a recent longitudinal study of 2,293 regularly attending adults, a total of 3,030 teeth (37\% of those that received treatment during the 5 years) were treated for caries. ${ }^{4}$ The increasing dentate elderly population are particularly vulnerable; $29 \%$ of dentate adults, aged $65+$, had root caries with an average of 2.3 teeth affected. ${ }^{5}$

In the UK, the prevalence of plaque and periodontal disease also remains high; ${ }^{3} 72 \%$ of dentate adults and 33\% of teeth had visible plaque and 54\% of adults had pocketing greater than $3.5 \mathrm{~mm}$. Although severe periodontal disease is relatively uncommon, with only $8 \%$ of dentate adults having loss of attachment of $6 \mathrm{~mm}$ or more, this increased to 31\% in those aged 65 and over. It was concluded that if large numbers of teeth are to be retained into old age there is a need to improve the oral cleanliness of the majority of the UK population. ${ }^{6}$

A search was made to identify systematic reviews on the Cochrane Library, DARE and Medline. A further search of Medline using "toothbrush"' as a free text term produced a vast list of publications too numerous to assess. A number of symposia which had reviewed relevant topics and provided consensus statements were sourced. The last search was conducted in June 2002. Using the data from these different sources we have made recommendations as to the advice dental professionals should give their patients about toothbrushing. The strength of evidence to support each recommendation will be indicated using the following hierarchy of evidence:

Type 1 Systematic review of at least one randomised controlled trial (RCT)

Type 2 At least one RCT

Type 3 Non-randomised intervention studies

Type 4 Observational studies

Type 5 Traditional reviews, expert opinion

Randomised controlled trials are accepted as the most robust study design but they may not be ethical or practical to undertake in certain areas. For example, observational studies have provided data on the reported frequency of 
toothbrushing and rinsing behaviour and should not be undervalued.

\section{CARIES}

\section{The role of oral hygiene}

The ubiquitous use of fluoride toothpaste makes it difficult to distinguish whether the effect of toothbrushing on caries is the result of the mechanical removal of plaque or a measure of fluoride application. ${ }^{7}$ Clearly the caries predilection sites, ie. occlusal pits and fissures and approximal surfaces are the most difficult to clean with toothbrush and toothpaste and traditional reviews (Type 5) of the literature have generally concluded that the effect of oral cleanliness per se on caries is equivocal. ${ }^{8,9}$ Prior to the widespread availability of fluoride toothpastes, evidence of the relative importance of oral hygiene and fluoride was provided by a 3-year study (Type 2) in which two groups of children, aged 9-11 years, had supervised brushing with or without a fluoride toothpaste whilst a control group received no supervision..$^{10}$ Both the supervised brushing groups had significantly reduced plaque and gingivitis scores when compared with the control group but a significant reduction in dental caries was only observed in the fluoride toothpaste group. It is generally accepted that the decline in dental caries can be attributed, primarily, to fluoride toothpaste ${ }^{11}$ and it would now be considered unethical to withhold the benefits of this from any group in a clinical trial.

Conclusion: The evidence that brushing per se is important in the prevention and control of caries is equivocal.

Evidence: Type 5

\section{FLUORIDE TOOTHPASTE}

It is generally accepted that the beneficial effects of fluoride toothpaste on dental caries are due to the topical effect of fluoride once the teeth have erupted. In contrast, the risk of fluorosis is due to the unintentional swallowing of toothpaste during tooth development. The parents of children less than 7 years should be strongly advised to apply only a small amount of toothpaste (pea or smear) and encourage the child to spit out.

A recent Cochrane Review (Type 1) concluded that the use of fluoride toothpaste is associated, on average, with a $24 \%$ reduction of dental caries in the permanent dentition of children and adolescents when compared with a non-fluoride toothpaste. ${ }^{12}$ The effect of fluoride toothpaste on the deciduous dentition was limited to one study, which reported a reduction of 37\% when compared with a non-fluoride toothpaste.

\section{Frequency of brushing}

The effectiveness of brushing twice daily with a fluoride toothpaste on caries is supported by data on reported behaviour (Type 4) obtained from surveys ${ }^{1,3}$ and clinical trials. ${ }^{13,14}$ For example, among children aged 3.5-4.5 years, $24 \%$ of those whose teeth were brushed more than once a day had caries experience compared with $38 \%$ of those whose teeth were brushed once a day and almost half (48\%) of those whose teeth were brushed less often. ${ }^{1}$ In clinical trials the 3-year caries increments in participants who reported brushing only once a day were 20-30\% more than those who brushed twice a day. ${ }^{13,14}$ Whilst these data need to be interpreted with some caution because of associations with other confounding factors, such as social class and sugar consumption, the weight and consistency of available evidence supports the recommendation that toothbrushing, with a fluoride toothpaste, should be performed twice daily. ${ }^{15}$

Recommendation: Brush twice daily with a fluoride toothpaste.

Evidence: (Type 4,5)

\section{Fluoride concentration}

In Europe, toothpastes containing a maximum fluoride concentration of $1500 \mathrm{ppm}$ are on general sale as cosmetic products. Formulations with higher concentrations are available as prescription only medicines.

An extensive review (Type 5) of clinical trials of fluoride toothpastes indicated that fluoride concentration is an important determinant of anticaries efficacy. ${ }^{16}$ Overall, the results suggest that within the range 1000 to $2500 \mathrm{ppm} F$ each increase of $500 \mathrm{ppm} F$ provides an additional 6\% reduction in caries. ${ }^{17}$

Low fluoride toothpastes, containing less than $600 \mathrm{ppm} \mathrm{F}$, are available for young children in the UK. A recent systematic review ${ }^{18}$ concluded that toothpastes containing 250 ppm F were not as effective at preventing caries in the permanent dentition as toothpastes containing 1000 ppm F or more (Type 1). Clinical trials in pre-school children (Type 2) comparing 550 ppm F with 1055 ppm F ${ }^{19}$ and 440 ppm F with 1450 ppm $\mathrm{F}^{20}$ have demonstrated that toothpastes containing the lower concentrations of fluoride provide less protection than those containing higher concentrations.

A number of randomised clinical trials ${ }^{21,22}$ have reported that toothpastes containing fluoride concentrations higher than 1500 ppm $F$ provide greater protection than toothpastes containing conventional levels of fluoride. Such a high fluoride toothpaste, containing 2800 ppm $\mathrm{F}$, has been launched recently as a prescription only toothpaste for high caries risk individuals over 16 years of age and particularly the elderly.

Recommendation: The appropriate fluoride concentration to recommend for an individual should be made after assessing their caries risk. This should involve an assessment of previous caries experience, the most powerful predictor of future caries ${ }^{23,24}$ together with a consideration of family history and socio-economic status.

A low fluoride concentration toothpaste $(<600 \mathrm{ppm} \mathrm{F})$ is appropriate for low caries risk children, less than 7 years of age, particularly if living in a fluoridated area.

A toothpaste containing a higher concentration of fluoride (1000-1450 ppm F) is appropriate for high caries risk children less than 7 years 
of age with the proviso that the parent applies only a pea-sized amount or smear to the toothbrush.

A high fluoride toothpaste (1450 ppm F) can be recommended for all individuals 7 years of age or older.

A toothpaste containing $2800 \mathrm{ppm} \mathrm{F}$ is appropriate for high caries risk adults and the elderly.

Evidence: (Type 1, 2)

\section{Rinsing behaviour}

An important determinant of anticaries efficacy of a fluoride toothpaste is the rinsing behaviour after brushing. The volume of water used and the vigour of rinsing after toothbrushing affect the fluoride concentration in the mouth and caries experience. ${ }^{25-27}$ Individuals should be advised not to rinse or to do so briefly with a small amount of water. Young children should be encouraged simply to spit out any excess toothpaste.

Recommendation: Discourage rinsing with large volumes of water. Encourage young children to spit out excess toothpaste.

Evidence: (Type 4,5)

\section{Amount of toothpaste}

Data concerning the effect that the amount of toothpaste has on efficacy is sparse. One clinical trial (Type 2) of dentifrices containing 1000, 1500 and 2500 ppm $F$ reported that the fluoride concentration was more important than the amount of toothpaste applied. ${ }^{28}$ Since very young children may swallow a large amount of toothpaste, ${ }^{29,30}$ thereby increasing the risk of fluorosis, parents should supervise very young children and place only a small amount of toothpaste ${ }^{31}$ (smear or pea size) on the brush. It is important to reinforce this advice since $31 \%$ of children aged 1.5 to 4.5 were reported to always brush their own teeth and $45 \%$ covered half the length of the brush or more. ${ }^{1}$

Recommendation: Toothbrushing by children should be supervised and only a smear or pea sized amount of toothpaste should be used.

Evidence: (Type 2,4,5)

\section{When to brush}

There is no evidence to indicate the relative anticaries benefits of brushing before or after eating meals. Recent surveys have reported that $61 \%$ of 1.5-4.5 year olds brush after breakfast and 52\% last thing at night ${ }^{1}$ for adults the values were $46 \%$ and $74 \%$ respectively. ${ }^{3}$ However, recent evidence ( Type 4) supports a recommendation that brushing with a fluoride toothpaste should take place just prior to going to bed; fluoride concentrations in saliva 12 hours after brushing last thing at night were comparable with those found 1-4 hours after brushing during the day. ${ }^{32}$

Recommendation: Brush last thing at night and on one other occasion.

Evidence: (Type 4,5)

\section{Type of fluoride}

There is some controversy regarding the comparative efficacy of the two major types of fluoride used in toothpastes; sodium fluoride $(\mathrm{NaF})$ and sodium monofluorophosphate (MFP). A systematic review (Type 1) suggested that $\mathrm{NaF}$ was superior to MFP ${ }^{33}$ but this was disputed. ${ }^{34}$ If any difference does exist between these two species it is unlikely to be of any clinical significance. Toothpastes containing either fluoride species can be recommended with confidence.

\begin{tabular}{|c|c|c|}
\hline & Instructions & Evidence \\
\hline Frequency of brushing & Brush twice a day with a fluoride toothpaste. & Type 4,5 \\
\hline Fluoride concentration & $\begin{array}{l}\text { The choice of fluoride concentration should be based } \\
\text { on the age and perceived caries risk of the individual } \\
\text { and their exposure to other fluoride sources. } \\
\text { A low fluoride concentration toothpaste } \\
\text { (<600 ppm F) is appropriate for low caries risk } \\
\text { children, < } 7 \text { years of age, particularly if living } \\
\text { in a fluoridated area. } \\
\text { A high fluoride toothpaste ( } 1450 \text { ppm F) is } \\
\text { appropriate for high caries risk, }<7 \text { years of age, } \\
\text { with the proviso that the parent applies only } \\
\text { a pea sized amount or smear to the toothbrush. } \\
\text { Such a concentration can be recommended to all } \\
\text { individuals over } 6 \text { years of age. } \\
\text { A toothpaste containing } 2800 \text { ppm F is appropriate } \\
\text { for high caries risk adults and the elderly. }\end{array}$ & Type 1,2 \\
\hline Amount of toothpaste & $\begin{array}{l}\text { Toothbrushing by children, }<7 \text { years of age, should } \\
\text { be supervised and only a pea sized amount or smear } \\
\text { of toothpaste should be used. }\end{array}$ & Type $2,4,5$ \\
\hline Rinsing behaviour & $\begin{array}{l}\text { Discourage rinsing with large volumes of water. } \\
\text { Encourage young children to spit out excess toothpaste. }\end{array}$ & Type 4,5 \\
\hline When to brush & Brush last thing at night and on one other occasion. & Type 4,5 \\
\hline Type of fluoride & $\begin{array}{l}\text { Toothpastes containing sodium fluoride, sodium } \\
\text { monofluorophosphate or stannous fluoride } \\
\text { are clinically effective. }\end{array}$ & Type 1,5 \\
\hline $\begin{array}{l}\text { Age to commence } \\
\text { brushing }\end{array}$ & $\begin{array}{l}\text { Advise parents/carers to begin brushing once the } \\
\text { primary teeth have commenced eruption. }\end{array}$ & Type 4,5 \\
\hline
\end{tabular}

The effectiveness of fluoride toothpaste is influenced by frequency, concentration and rinsing behaviour; frequency having the greatest impact 


\section{The profession should advise and encourage individuals to maintain an effective level of oral hygiene}

Recommendation: Toothpastes containing sodium fluoride, sodium monofluorophosphate or a combination are clinically effective.

Evidence: (Type 1, 5)

\section{Age to commence brushing}

Several studies have reported an association between the age that toothbrushing was claimed to have commenced and caries experience (Type 4). Overall, $12 \%$ of $1.5-4.5$ year olds who started to brush before the age of 1 year had some caries experience (active decay, filled teeth or teeth missing due to decay) compared with $19 \%$ who started between the ages of 1 and 2 years and $34 \%$ of those who did not start toothbrushing until after the age of 2 years. ${ }^{1}$ Again, these data need to be treated with caution because of confounding factors.

Recommendation: Advise parents/carers to commence brushing once the primary teeth have commenced eruption.

Evidence: (Type 4,5)

\section{PERIODONTAL DISEASE}

Although plaque is the primary aetiological agent for periodontal disease it is evident that there is considerable variation in the extent and severity of tissue destruction between individuals, teeth and tooth sites. ${ }^{6}$ The aim is to maintain a level of plaque control which ensures that the rate of tissue destruction is reduced sufficiently to ensure that most individuals maintain a comfortable and functional natural dentition for life. However, the level of plaque control required varies from individual to individual.

The oral care industry continues to try and provide the public with toothbrushes and toothpastes that improve the effectiveness of plaque control and periodontal health. The efficacy of these different products has been evaluated in numerous clinical trials the results of which have been the subject of a number of traditional reviews. ${ }^{35,37}$

\section{Frequency of brushing}

The effective removal of plaque every second day has been shown to prevent gingivitis ${ }^{38}$ and resolve experimental gingivitis; ${ }^{39}$ the less frequent removal of plaque did not prevent or reduce gingivitis. No optimum frequency has been determined but there is a consensus that twice daily brushing is consistent with maintaining good gingival health..$^{35,40}$

Recommendation: Brush twice daily. Evidence: (Type 5)

\section{Brushing duration and technique}

Individuals rarely brush for the length of time they say they $\mathrm{do}^{41-43}$ and rarely exceed $60 \mathrm{sec}-$ onds. ${ }^{44,45}$ Most use a simple horizontal brushing action, spend little time brushing lingual areas, and fail to remove plaque effectively from the approximal surfaces of premolars and molars. ${ }^{46}$ Traditional reviews of the literature (Type 5) have concluded that no particular method is superior to any other and it is more realistic to modify the patient's existing method of brushing, emphasising the need to repeat the procedure on all available tooth surfaces. ${ }^{35,47}$

Recommendation: Modify existing method of brushing, emphasising a systematic approach to maximise plaque removal.

Evidence: (Type 5)

\section{Manual toothbrushes}

The published literature on the relative merits of different manual toothbrushes is extensive. In general (Type 5) it is accepted that toothbrushes should have the following attributes: a handle size appropriate to the user's age and dexterity, a head size appropriate to the user's mouth, a compact arrangement of soft, end rounded nylon filaments not larger than 0.009 inches in diameter and bristle patterns which enhance plaque removal in the approximal spaces and along the gum margin. ${ }^{48}$ In an effort to improve the efficacy of plaque removal toothbrushes with filaments arranged at different heights and angles have been developed. Several randomised controlled studies (Type 2) have demonstrated that these designs were significantly more effective at removing plaque ${ }^{49,50}$ and reducing gingivitis ${ }^{52}$ than flat trim brushes.

Recommendation: Use a small headed brush with soft, round ended filaments, a compact, angled arrangement of long and short filaments and comfortable handle.

Evidence: (Type 2,5)

\section{Powered toothbrushes}

Most modern powered toothbrushes have a small, circular head which performs oscillating, rotating or counter-rotational movements. Timers are now being introduced into the design giving the user feedback on the duration of brushing. Numerous clinical trials have been performed comparing the efficacy of such toothbrushes with other models or manual toothbrushes. Traditional reviews ${ }^{53}$ have generally concluded (Type 5) that powered toothbrushes are more effective in removing plaque, and in some instances reducing gingivitis, than manual toothbrushes. ${ }^{3}$ A recent Cochrane Review ${ }^{54}$ concluded (Type1) that powered toothbrushes with an oscillating/rotating movement were more effective in removing plaque and reducing gingivitis than a manual toothbrush. Two studies have reported that powered toothbrushes improved compliance. ${ }^{55,56}$ Ideally dental professionals should provide advice and instruction in the use of these devices. ${ }^{57}$

Recommendation: For those individuals who are unable to maintain an effective level of plaque control and periodontal health powered brushes with an oscillating/rotating action may be more effective than manual brushes.

Evidence: (Type 1,5)

\section{Toothpaste}

Since most individuals are unable to maintain an effective level of plaque control by mechanical means alone, various chemical agents have 
been added to toothpastes to enhance the removal of plaque and thereby improve periodontal health. The most widely used agent in toothpastes is triclosan, a broad-spectrum antibacterial agent. The effectiveness of triclosan formulations has been improved by either adding a copolymer to enhance its retention in the mouth or by adding zinc citrate to provide additional antibacterial activity. These formulations have been shown in randomised controlled trials (Type 2) to provide significant reductions in plaque and significant improvements in gingival health ${ }^{58,59}$ when compared with a fluoride toothpaste alone. In studies of 3 years duration the triclosan/copolymer formulation was reported to reduce the onset of periodontitis in adolescents $^{60}$ and the further progression of periodontitis in at- risk adults. ${ }^{61}$

Recommendation: Use toothpastes which contain triclosan with either copolymer or zinc citrate to improve levels of plaque control and periodontal health.

Evidence: (Type 2)

\section{PROFESSIONAL INVOLVEMENT}

The profession has a wider responsibility for preventing and controlling dental diseases than simply providing toothbrushing advice. The effectiveness of intensive professional involvement in preventive programmes has been well documented in a number of longitudinal studies. In a 4-year trial (Type 2) children, aged 7-14 years, were allocated to test and control groups. ${ }^{62}$ During the first 2 years those in the test group received oral hygiene instruction, a professional prophylaxis and topical application of sodium monofluorophosphate every 2 weeks. During the third year this programme was repeated once a month and in the final year every 2 months. The control group brushed their teeth with a $0.32 \%$ solution of sodium fluoride once a month throughout the 4 years. Children in the test group had virtually no plaque and gingivitis and had a very small caries increment when compared with the control group. A similar programme was evaluated in adults (Type 2) over a 6 -year period. ${ }^{63}$ During the first 2 years the test group received preventive measures every 2 months and during the subsequent 4 years every 3 months. The preventive measures comprised: instruction and practice in oral hygiene with emphasis on interdental cleaning, a professional prophylaxis and topical application of fluoride. The control group was recalled at yearly intervals and received conventional care. The preventive programme improved periodontal health and reduced the progression of periodontitis and the incidence of caries when compared with the control group. During a further 9 years the test group continued to receive the preventive programme at varying intervals depending on perceived risk. ${ }^{64}$ Sixty-five per cent of subjects were recalled once a year, 30\% twice a year and 5\% at 2-4 monthly intervals. The results demonstrated that the programme effectively prevented recurrence of dental disease in all but a small number of highly susceptible individuals.

Whilst such studies clearly indicate the effectiveness of a combination of personal and professional plaque control measures in controlling dental diseases, the frequency of recall which ranged from 2 weeks to 4 months is probably unrealistic for most patients and practices.

\section{SUMMARY}

The advice that dental practitioners and hygienists give to their patients on toothbrushing should be based on the best available evidence, with due consideration being given to the individual patient's ability to achieve and maintain an acceptable level of oral health. Increasingly, systematic reviews ${ }^{12,54,65}$ and Clinical Guidelines ${ }^{66,67}$ are being published to support recommendations. This review indicates that much of what we advise is based on traditional reviews of the literature in which the selection of studies does not entail an appraisal of their quality. However, the number of high quality systematic reviews is increasing and will provide stronger evidence to support the advice we give and Clinical Guidelines.

Most people perceive toothbrushing as a tedious procedure which is performed primarily to provide cosmetic rather than health benefits. The increasing popularity of powered brushes and fluoride toothpastes which contain agents that also improve plaque control and periodontal health are to be welcomed. Clinician's can maximise the health benefits of this process by advising patients about frequency, choice of

\section{Despite improve- ments in oral health there is still the potential for many individuals to gain greater benefit. The clinician has a clear role in providing appropriate advice to enable patients to maximise the effects of toothbrushing. Future services should recognise and support the profession in this role}

\begin{tabular}{lll}
\hline \multicolumn{2}{l}{ Table $\mathbf{2}$ The levels of evidence for recommendations for control of periodontal disease } & \\
\hline Frequency of brushing & Instructions & Evidence \\
\hline Brushing duration and technique & Twice daily & Type 5 \\
\hline Manual toothbrushes & $\begin{array}{l}\text { Modify existing method of brushing } \\
\text { emphising a systematic approach. }\end{array}$ & Type 5 \\
\hline Powered toothbrushes & $\begin{array}{l}\text { Small headed; soft, round ended filaments; } \\
\text { compact, angled arrangement of long and short } \\
\text { filaments; comfortable handle. }\end{array}$ & Type 2,5 \\
\hline Toothpaste & $\begin{array}{l}\text { Powered brushes may be more effective than } \\
\text { manual brushes. }\end{array}$ & Type 1,5 \\
& $\begin{array}{l}\text { Toothpastes containing triclosan with either } \\
\text { copolymer or zinc citrate provide improved } \\
\text { levels of plaque control and periodontal health. }\end{array}$ & Type 2
\end{tabular}


toothpaste and brush, post-brush rinsing and the supervision of children.

In the UK only $62 \%$ of dentate adults recalled having been given some advice or information about toothbrushing or gum care. Patients should be given advice and encouragement to achieve and maintain an acceptable level of oral health. The advice should be tailored to the individual and reinforced at regular intervals if the desired behaviour and benefits are to be sustained.

Affiliation: Robin Davies and Roger Ellwood are employees of Colgate-Palmolive (UK) Ltd.

1. Hinds K, Gregory J R. National Diet and Nutrition Survey; children aged 1.5 to 4.5 years. Vol 2: Report of the Dental Survey. London: The Stationery Office, 1995.

2. Walker A, Gregory J, Bradnock G, Nunn J, White D. National Diet and Nutrition Survey: young people aged 4 to 18 years. Vol 2: Report of the Oral Health Survey. London: The Stationery Office, 2000

3. Kelly M, Steele J, Nuttall N et al. Adult Dental Health Survey: Oral Health in the United Kingdom 1998. Walker A, Cooper I, (eds) London: The Stationery Office, 2000.

4. Clarkson J E, Worthington HV, Davies R M. Restorative treatment provided over five years for adults regularly attending general dental practice. J Dent 2000; 28: 233-239.

5. Nunn J, Morris J, Pine C, Pitts N B, Bradnock G, Steele J. The conditions of teeth in the UK in 1998 and implications for the future. Br Dent J 2000; 189: 639-644.

6. Morris A J, Steele J, White D A. The oral cleanliness and periodontal health of UK adults in 1998. Br Dent J 2001; 191: 186-192.

7. Reisine ST, Psoter W. Socioeconomic status and selected behavioural determinants as risk factors for dental caries. J Dent Educ 2001: 65:1009-1016.

8. Sutcliffe P. Oral cleanliness and dental caries. In Murray J J (ed) Prevention of oral diseases. pp 68-77. Oxford: Oxford University Press, 1996.

9. Hotz P R. Dental plaque control and dental caries. In Lang N P, Attstrom R, Loe H (eds) Proceedings of the European Workshop on Mechanical Plaque Control. pp 35-49. Chicago: Quintessence, 1998.

10. Koch $\mathrm{G}$, Lindhe J. The state of the gingivae and caries increment in school children during and after withdrawal of various prophylactic measures. In McHugh W D (ed) Denta Plaque.pp 271-281. Edinburgh: Livingstone, 1970.

11. Bratthall $D$, Hansel Peterson $G$, Sundberg $H$. Reasons for the caries decline: what do the experts believe? Euro J Oral Sci 1996; 104: 416-422.

12. Marinho V C C, Higgins J PT, Sheiham A, Logan S. Fluoride toothpastes for preventing dental caries in children and adolescents (Cochrane Review). In: The Cochrane Library, Issue 1.2003. Oxford: Update Software.

13. Chesters R K, Huntington E, Burchell C K, Stephen K. W. Effect of oral care habits on caries in adolescents. Caries Res 1992; 26: $299-304$

14. Chestnutt IG, Schafer K, Jacobson A P M, Stephen KW. The influence of toothbrushing frequency and post-brushing rinsing on caries experience in a caries clinical trial. Community Dent Oral Epidemiol 1998; 26: 406-411.

15. The Scientific Basis of Dental Health Education: A Policy Document(revised fourth edition). Health Development Agency 2001.

16. Clarkson J E, Ellwood R P, Chandler R E. A comprehensive summary of fluoride dentifrice caries clinical trials. Am J Dent 1993; 6: (Spec Iss) S59-S106.

17. Stephen $\mathrm{K}$ W, Creanor S L, Russell J I et al. A 3 year oral health dose response study of sodium monofluorophosphate dentifrices with and without zinc citrate: anticaries results. Community Dent Oral Epidemiol 1988; 16: 321-325.

18. Ammari A B, Bloch-Zupan A, Ashley P F. Systematic review of studies comparing the anti-caries activity of children's toothpaste containing 600 ppm of fluoride or less with high fluoride toothpastes of 1,000 ppm or above. Caries Res 2003; 37: 85-92.

19. Winter $G$ B , Holt R D, Williams B F. Clinical trial of a low fluoride tooth paste for young children. Int Dent J 1989; 39 : 227-235.

20. Davies G M, Worthington HV, Ellwood R P etal. A randomised controlled trial of the effectiveness of providing free toothpaste from the age of 12 months on reducing caries in 56-year old children. Community Dental Health 2002: 19: 131-136.

21. Marks R G, D'Agostino R, Moorhead J E et al. A fluoride dose response evaluation in an anti-caries clinical trial. J Dent Res 1992; 71: 1286-1291

22. Biesbrock A R, Gerlach R W, Bollmer B W, Faller R V, Jacobs $S$ A, Bartizek R D. Relative anti-caries efficacy of 1100, 1700, 2200 , and $2800 \mathrm{ppm}$ fluoride ion in a sodium fluoride dentifrice over 1 year. Community Dent Oral Epidemiol 2001. 29: 382-389.

23. Hausen H. Caries prediction-state of the art. Community Dent Oral Epidemiol 1997; 25: 87-96.

24. Disney J A, Graves R C, StammJ W, Bohannon H M, Abernathy J R, Zack D D, The University of North Carolina Caries Risk Assessment study: further developments in caries risk prediction. Community Dent Oral Epidemio/ 1992; 20: 64-75.

25. O'Mullane D M, Kavanagh D, Ellwood R P et al. A three year clinical trial of a combination of trimetaphosphate and sodium fluoride in silica toothpastes. J Dent Res 1997; 76: 1776-1778.

26. Duckworth R M, Morgan S N. Oral fluoride retention after use of fluoride dentifrices. Caries Res 1991; 25: 123-129.

27. Sjogren $\mathrm{K}$, Birkhed $D$. Factors related to fluoride retention after toothbrushing and possible connection to caries activity. Caries Res 1993; 27: 474-477.

28. Duckworth R M, Morgan S N, Murray A M. Fluoride in saliva and plaque following use of dentifrices containing sodium monofluorophosphate. J Dent Res 1989; 68: 130-133.

29. Bentley E M. Ellwood R P, Davies R M. Fluoride ingestion from tooth paste by young children. Br Dent J 1999; 186: 460-462.

30. Levy S M. Review of fluoride exposures and ingestion. Community Dent Oral Epidemiol 1994: 22: 173-180.

31. British Society of Paediatric Dentistry: A policy document on fluoride dietary supplements and fluoride toothpastes for children. Int J Paed Dent 1996; 6: 139-142.

32. Duckworth R M, Moore SS. Salivary fluoride concentrations after overnight use of tooth pastes. Caries Res 2001; 35: 285

33. Johnson M F. Comparative efficacy of NaF and SMFP dentifrices in caries prevention: a meta-analytic overview. Caries Res 1993: 27: 328-336.

34. Holloway PJ, Worthington H V. Sodium fluoride or sodium monofluorophosphate? A critical review of a meta-analysis on their relative effectiveness in dentifrices. Am J Dent 1993; 6: (Spec Iss) S55-S58.

35. Jepsen $\mathrm{S}$. The role of manual toothbrushes in effective plaque control: Advantages and limitations. In Lang NP, Attsrom R, Loe H. (eds) Proceedings of the European Workshop on Mechanical Plaque Removal. pp 121-137.Chicago: Quintessence, 1998.

36. van der Weijden G A, Timmerman M F, Danser M M, van der Velden $U$. The role of electric toothbrushes: Advantages and Limitations. In Lang N P, Attstrom R, Loe H (eds) Proceedings of the European Workshop on Mechanical Plaque Control.pp 138-155. Chicago: Quintessence, 1998.

37. Adriaens PA, Gjermo P. Anti-plaque and anti-gingivitis efficacy of toothpastes. In Lang N P, Karring T, Lindhe J. (eds) Proceedings of the 2nd European Workshop on Periodontology. Chemicals in periodontics. pp 204-220. Chicago: Quintessence, 1997.

38. Lang N P, Cumming B R, Loe $H$. Toothbrushing frequency as it relates to plaque development and gingival health. J Periodont 1973; 44: 396-405.

39. Bosman C W, Powell R N. The reversal of localized experimental gingivitis. J Clin Periodontol 1977; 4: 161-172.

40. Addy M, Adriens P. Consensus report of Group A. Epidmiology and etiology of periodontal diseases and the role of plaque control in dental caries. In Lang N P, Attstrom $\mathrm{R}$, Loe H (eds) Proceedings of the European Workshop on Mechanical Plaque Control. pp 98-101. Chicago: Quintessence, 1998.

41. Macgregor I D M, Rugg-Gunn A J. A survey of toothbrushing duration in 85 uninstructed English school children Community Dent Oral Epidemio/ 1979; 7: 297-298.

42. Cancro L P, Fischman S L. The expected effect on oral health of dental plaque control through mechanical removal. Periodonto/2000 1995; 8: 60-74.

43. Saxer U P. Emling R C Yankel SL Actual vs estimated tooth brushing time and tooth paste used. Caries Res 1983; 17: 179-180.

44. Rugg-Gunn A J, MacGregor I D M. A survey of toothbrushing 
behaviour in children and young adults. J Perio Res 1978; 113: 382-388.

45. Yankell S L. Toothbrushing and toothbrushing techniques In Harris N 0, Christen A G. (eds) Primary preventive dentistry.3rd ed. Norwalk C T: Appleton and Lange, 1991.

46. Hawkins R J, Zanetti D L, Main P A et al. Toothbrushing competency among high-risk grade one students: an evaluation of two methods of dental health education. J Public Health Dent 2001; 61: 197-202.

47. Egelberg J. Oral Hygiene Methods, The Scientific Way, Synopsis of Clinical Studies. p13 Malmo: OdontoScience, 1999.

48. Egelberg J, Claffey N. Role of mechanical dental plaque removal in prevention and therapy of caries and periodontal diseases. In Lang N P, Attstrom, R, Loe, H (eds) Proceedings of the European Workshop on Mechanical Plaque Control.pp 169-172. Chicago: Quintessence, 1998.

49. Balanyk TE, Sharma N C, Galustians J. A clinical study of comparative plaque removal performance of two manual toothbrushes. J Clin Dent 1993; 4: (Suppl D) D8-D12.

50. Sharma N C, Rustogi K N, McCool J J et al. Comparative plaque removal efficacy of three toothbrushes in two independent clinical studies. J Clin Dent 1992; 3: (Suppl C) C13-C28.

51. Cronin M J, Dembling W Z, Low M L, Jacobs D M, Weber D A. A comparative clinical investigation of a novel toothbrush designed to enhance plaque removal efficacy. Am J Dent 2000; 13: (Spec Iss) 21A-26A.

52. Sharma N C, Galustians J, McCool J J, Rustogi K N, Volpe A R The clinical effects on plaque and gingivitis over 3 months use of four complex design manual toothbrushes. J Clin Dent 1994; 5: 114-118.

53. Heasman PA, McCracken G I. Powered toothbrushes: a review of clinical trials. J Clin Periodontol 1999; 26: 407-420.

54. Heanue M, Deacon S A, Deery C et al. Manual versus powered toothbrushing for oral health. (Cochrane Review). In:The Cochrane Library, Issue 1. 2003. Oxford. Software Update.

55. Hellstadius K, Asman B, Gustafsson A. Improved maintenance of plaque control by electrical toothbrushing in periodontitis patients with low compliance. J Clin Periodontol 1993; 20: 235-237

56. Stalnacke K, Soderfelt B, Sjodin B. Compliance in use of electric toothbrushes. Acta Odont Scand 1995; 53: 17-19.

57. Renton-Harper P, Addy M, Newcombe R G. Plaque removal with the uninstructed use of electric toothbrushes; comparison with a manual brush and toothpaste slurry. J Clin Periodontol 2001; 28: 325-330.

58. Svatun B, Saxton CA, Rolla G, van der Ouderaa F G H. A 1-year study on the efficacy of a dentifrice containing zinc citrate and triclosan to maintain gingival health. Scand J Dent Res 1989; 97: 242-246.

59. Volpe A R, Petrone M E, DeVizio W, Davies R M, Proskin H M. A review of plaque, gingivitis, calculus and caries clinical efficacy studies with a fluoride dentifrice containing triclosan and PVM /MA copolymer. J Clin Dent 1996; 7 (Suppl): S1-S14.

60. Ellwood R P, Worthington H.V, Blinkhorn AS B, Volpe A R, Davies R M. Effect of a triclosan/copolymer dentifrice on the incidence of periodontal attachment loss in adolescents. J Clin Periodonto/ 1998; 25: 363-367.

61. Rosling B, Wannfors B, Volpe A R, Furuichi Y, Ramberg P, Lindhe J. The use of a triclosan/copolymer dentifrice may retard the progression of periodontitis. J Clin Periodontol 1997: 24: 873-88.

62. Axelsson $P_{1}$ Lindhe J. The effect of a plaque control program on gingivitis and dental caries in schoolchildren. J Dent Res 1977; 56 (Spec Iss C): C142-C148

63. Axelsson $\mathrm{P}$, Lindhe J. Effect of controlled oral hygiene procedures on caries and periodontal disease in adults. Results after 6 years. J Clin Periodontol 1981; 8: 239-248.

64. Axelsson P, Lindhe J, Nystrom B. On the prevention of caries and periodontal disease. Results of a 15-year longitudinal study. J Clin Periodontol 1991; 18: 182-189.

65. NIH Consensus Development Conference on Diagnosis and Management of Dental Caries throughout life. J Dent Educ 2001; 65: 935-1179.

66. National Clinical Guidelines 1997. London: The Royal College of Surgeons of England.

67. Health Evidence Bulletins Wales, Oral Health. Cardiff. Welsh Office. 1998. 